\title{
UMA REESCRITA BRASILEIRA DE REI LEAR: DE TRAGÉDIA APOCALÍPTICA A DRAMA FAMILIAR
}

\author{
Marcia Amaral Peixoto Martins ${ }^{1}$ \\ 'Pontifícia Universidade Católica do Rio de Janeiro, \\ Rio de Janeiro, Rio de Janeiro, Brasil
}

Liana de Camargo Leão²

${ }_{2}^{2}$ Universidade Federal do Paraná, Curitiba, Paraná, Brasil

\begin{abstract}
Resumo: O foco deste trabalho é uma produção de 2014 do Rei Lear de Shakespeare, traduzida e adaptada por Geraldo Carneiro, dirigida por Elias Andreato e protagonizada por Juca de Oliveira, que sozinho no palco dá vida a seis personagens. $\mathrm{O}$ ator assume a voz de um narrador e também incorpora os diferentes personagens, enunciando suas falas e, muitas vezes, estabelecendo um diálogo entre eles. Serão objeto de análise as principais características do texto dessa montagem, a saber: (I) o enxugamento da ação, com o corte da subtrama envolvendo o duque de Gloucester e seus dois filhos, Edmund e Edgar, e um final antecipado, que encerra a peça com o reencontro entre Lear e Cordelia, sem chegar ao desfecho trágico da morte de ambos; (II) o emprego do recurso da narração, situando Lear, narrador-protagonista, em um momento cronológico à frente dos fatos que ocorreram; (III) o emprego do recurso do diálogo entre Lear e os outros cinco personagens da trama, em que o ator vive os diferentes papéis e "encena" as interações; (IV) o emprego de uma combinação de prosa, versos brancos e versos rimados nas falas, seguindo o padrão da poesia dramática shakespeariana; e $(\mathrm{V})$ a presença de interpolações de fragmentos de outras obras de Shakespeare. Aspectos ligados diretamente à montagem, tais como cenário e figurino, também serão examinados.
\end{abstract}

Palavras-chave: Adaptação teatral; William Shakespeare; Rei Lear. 


\title{
A BRAZILIAN REWRITING OF KING LEAR: FROM APOCALYPTIC TRAGEDY TO FAMILY DRAMA
}

\begin{abstract}
The purpose of this article is to analyze a 2014 production of Shakespeare's King Lear translated and adapted by Geraldo Carneiro, directed by Elias Andreato, and starring Juca de Oliveira in a solo performance in which he plays six roles. The actor performs the role of a narrator and also incorporates the different characters, speaking their lines and quite often establishing a dialogue between them. The main features of the adapted text will be examined, namely: (I) the cuts in the plot, resulting in the omission of the subplot involving the Duke of Gloucester and his two sons, Edmund and Edgar, and in an early ending, at the point when Lear and Cordelia are reunited, without ever reaching the tragic denouement with both of them dying; (II) the use of narration, placing Lear, the narrator-protagonist, in a chronological time ahead of the action he describes; (III) the use of dialogue between Lear and the other five characters of the play, in which the single actor simultaneously plays different characters in interaction; (IV) the use of a combination of prose, blank verse and rhyming verse following the pattern of Shakespeare's dramatic poetry; and (V) the presence of interpolated fragments of other works by Shakespeare. Aspects directly linked to the staging, such as scenery and costume design, will also be examined.
\end{abstract}

Keywords: Stage adaptation; William Shakespeare; King Lear.

A proposta deste trabalho é analisar uma produção de 2014 do Rei Lear de Shakespeare, traduzida e adaptada por Geraldo Carneiro, dirigida por Elias Andreato e protagonizada por Juca de Oliveira, que sozinho no palco dá vida a seis personagens. Por 400 anos, Rei Lear tem sido adaptada e reescrita por dramaturgos, romancistas e roteiristas de cinema e televisão. A peça, que integra as chamadas quatro grandes tragédias shakespearianas, ao lado de Hamlet, Macbeth e Otelo, foi escrita em 1605-1606, já na maturidade do dramaturgo. Seu protagonista é Lear, rei da Bretanha, que chegando à velhice decide dividir seu reino entre as três filhas, mas para isso quer saber a extensão do amor que cada uma tem por ele. Enquanto as duas mais velhas exageram na sua devoção, a mais moça, Cordelia, declara amar o pai conforme o seu dever, "nem 
mais, nem menos" ${ }^{1}$. Enfurecido e profundamente decepcionado, Lear deserda Cordelia, até então sua preferida, e divide o reino entre as filhas Goneril e Regan, pretendendo morar com uma e com outra, alternadamente, junto com um séquito de 100 homens. Logo as duas começam a desrespeitar o acordo, alegando ser impossível conviver com os serviçais do pai. Diante do ultimato das filhas ou ele se livra do séquito ou elas se recusarão a hospedá-lo - Lear deixa o castelo do amigo Gloucester em meio a uma tempestade iminente. Em um descampado, tendo apenas como companhia o Bobo, o fiel amigo Kent e Edgar, o filho banido de Gloucester, Lear perde a razão, fato que, contraditoriamente, lhe propicia uma viagem de autoconhecimento. Na visão de Barbara Heliodora, o processo do aprendizado de Lear é extraordinariamente doloroso, no qual o Bobo tem papel fundamental: "mais do que engraçado, a função do personagem é a de servir de consciência de Lear até este, depois da crise na tempestade, passar a ter ele mesmo consciência de seus atos” (2006, p. 757). Complementa Nelson de Sá: “Em lugar da loucura e depois da infantilização de Lear, seu bobo traz lucidez e distanciamento, desnudando o autoengano do rei [...]" (SÁ, 2014, [s.p.]). Nesse meio tempo, Cordelia e o rei da França, seu marido, que a quis mesmo deserdada, vêm ao seu encontro com tropas francesas para enfrentar o exército dos genros Albany e Cornwall. Após a reconciliação entre Lear e a filha mais querida, os franceses são derrotados; as irmãs Goneril e Regan morrem em decorrência de uma disputa pelo amor de Edmund, o filho cruel de Gloucester; e Cordelia é enforcada na prisão e levada até Lear, que a segura nos braços e morre em seguida.

Barbara Heliodora assim analisa as atitudes de Lear:

Como sempre, em Shakespeare, o mal é ligado a um ato de transgressão contra a natureza: não há nada de errado em Lear dividir seu reino entre as filhas, pois há exemplos

1 "I love your majesty//According to my bond, no more, no less" (I.i. 92-93, SHAKESPEARE, 1988). 
históricos de atos semelhante. Onde ele erra, onde ele transgride a natureza, é na recusa em compreender o justo amor de Cordelia, preferindo acreditar nas bajulações de Goneril e Regan, e deserdando a caçula. A par disso, também erra quando quer se livrar das responsabilidades de rei mas continuar a gozar dos privilégios do cargo. Para Shakespeare, direitos e deveres são indissociáveis e, quando Lear afirma querer se livrar de suas obrigações e "se arrastar sem cargas para a morte", ele não tem ideia de que até que ponto esse seu suposto desejo será realizado. (2016, p. 756)

A fortuna da peça é bastante extensa, sendo frequentes as adaptações e montagens, algumas muito felizes, outras nem tanto. No teatro, a partir de 1681 ganhou predominância a versão de Nahum Tate, que eliminou personagens, como o Bobo, e alterou drasticamente a trama, a ponto de criar um final feliz com o casamento entre Cordelia e Edgar, o filho legítimo de Gloucester, que também havia sido deserdado devido a maquinações do irmão bastardo. Durante 150 anos, "a versão de Tate foi praticamente a única aceita pelas plateias" (TREWIN, 1994, p. 122)2 ${ }^{2}$, embora David Garrick tenha criado uma um pouco diferente, mantendo o enredo de Tate mas recuperando os versos originais, que foi apresentada no Drury Lane durante cerca de 30 anos a partir de 1756 (ibid.). O original elisabetano foi sendo restaurado aos poucos, até que o ator William Charles Macready encenou, em 1838, uma versão condensada do texto.

No cinema, a trajetória de Lear se inicia ainda na época dos filmes mudos, com duas produções norte-americanas, a da Vitagraph (1909) e a da Tranhouser Film Corporation (1916), dirigidas, respectivamente, por William V. Ranous e Ernest C. Wade, e uma italiana, da Film d'Arte Italiana (1910), tendo como diretor Gerolamo Lo Savio. Já em meados do século, duas recriações da história se destacaram: House of Strangers (1949), dirigida por

${ }^{2}$ Todas as citações extraídas de obras publicadas em língua inglesa são de nossa autoria.

Cad. Trad., Florianópolis, v. 38, n⿳ 3, p. 159-182, set-dez, 2018 
Joseph Mankiewicz, e Broken Lance (1956), dirigida por Edward Dmytryk, ambas produzidas pela Fox.

Em 1970 é lançado, no congresso da International Shakespeare Association no Canadá, o filme até hoje considerado como o melhor Lear do cinema. Dirigido pelo russo Grigori Kozintsev e produzido pelo Lenfilm Studio, o filme foi praticamente contemporâneo da versão do célebre diretor shakespeariano Peter Brook, em 1971. Muitas outras adaptações e reescritas se seguiram, destacando-se a versão japonesa Ran, dirigida por Akira Kurosawa, em 1985; o polêmico Lear de Jean-Luc Goddard, em 1987; e, mais recentemente, a produção estrelada e dirigida por Brian Blessed, em 1999.

$\mathrm{Na}$ televisão, além das adaptações pela BBC, de 1948, 1982 e 1998, as mais célebres são a versão estrelada por Patrick McGee, em 1976, e a do então adoentado e prematuramente envelhecido Laurence Olivier, que data de 1983. Produções teatrais importantes também foram televisionadas e lançadas em DVD, como a aclamada montagem de 2007 dirigida por Trevor Nunn e protagonizada por Ian Mckellen.

Também a literatura tem sido alimentada pela história de Lear. Uma recente e aclamada reescrita é o romance Still Time (2015), de Jean Hegland, que conta a história de um professor shakespeariano que começa a sofrer de demência e que, tendo se afastado da filha ao longo da vida, a reencontra ao final.

Este passeio pela história das montagens, adaptações e reescritas de Lear tem objetivo de situar o leitor quanto à proposta brasileira. O texto de Shakespeare foi adaptado para um espetáculo solo; Juca de Oliveira é o único ator no palco, revezando-se em seis papéis: as filhas Goneril, Regan e Cordelia, Kent e o Bobo, além do próprio rei, que narra a ação. Como observa Nelson de Sá em sua crítica, "Não se trata de um monólogo, mas de um solo em que o ator faz vários papéis, como nas celebradas versões de Bob Wilson e Robert Lepage para 'Hamlet'” (SÁ, 2014, [s.p.]). Tal concepção é, até onde se sabe, inédita na história de montagens de Lear. $\mathrm{O}$ ator

${ }^{3}$ O DVD foi lançado em 2008. 
assume a voz de um narrador e também incorpora os diferentes personagens, enunciando suas falas e, muitas vezes, estabelecendo um diálogo entre eles. Tais escolhas implicam, naturalmente, em limitações: como recontar uma das obras-primas de Shakespeare, talvez sua peça mais complexa, que conta com 18 personagens com falas (além de cavaleiros do séquito do rei, oficiais, mensageiros, soldados e criados) e uma subtrama, e tem duração média de três horas, com 3.216 linhas de texto ${ }^{4}$, em cerca de uma hora? O que será privilegiado e o que será suprimido?

De modo breve, a montagem reduz uma peça de dimensões cósmicas e descrita como uma visão do apocalipse a uma crise em família. Como observa Sá,

[a] adaptação opta pelo núcleo familiar e dramático, sacrificando aquele mais político e propriamente trágico dos outros personagens de importância na peça, como Edgar, Edmund e Gloucester (2014, [s.p.]).

Ainda assim, a história continua a exercer seu poder sobre as plateias que testemunham a degradação física e psicológica do protagonista. Para Peter Ackroyd, em Shakespeare: The Biography, "[a]ssistir a Rei Lear é se aproximar do reconhecimento de que de fato a vida não tem sentido e que há limites para a compreensão humana" (2006, p. 436).

Outro aspecto que caracteriza essa montagem é a ênfase na redenção, por meio do reencontro e reconciliação com Cordelia. No original, à reconciliação se segue o final trágico, com a morte de Cordelia e do próprio Lear, além das de Gloucester, Edmund e das filhas mais velhas. A culpados e inocentes está reservado o mesmo destino. Para Sá,

É como se 'Rei Lear' se fechasse em uma de suas fontes, aquela dos contos de fadas mais ou menos próximos de Cin-

${ }^{4}$ Shakespeare, 1959. 
derela: as duas filhas malvadas que fingem amar e assim enganam o pai, enquanto aquela que o ama de verdade, Cordelia, é perseguida" (2014, [s.p.]).

A montagem brasileira, no entanto, termina com Lear e Cordelia vivos, como será abordado mais adiante.

Um dos temas centrais da peça, a relação entre pais e filhos, é amplificado no original pelo espelhamento entre a trama principal e a subtrama. A história de Gloucester e seus filhos reproduz e intensifica a de Lear e suas filhas, de modo que Gloucester se transforma "não apenas em uma figura 'paralela' a Lear, mas no seu duplo” (CAVELL, 1987, p. 52). Irving Ribner considera Gloucester um Lear menos nobre, pertencente a um estrato social menos elevado, de modo que é pelo espelhamento dos enredos que a tragédia ganha validade universal (1960, p. 117). Outros críticos também destacam o subenredo como fundamental para a construção do sentido da peça:

o mestre, sendo mestre, não errou na duplicação do enredo; a situação e experiência vivida pela família de Gloucester intensificam o efeito produzido pelaa situação e experiências vividas pela família de Lear; e, novamente, os dois enredos se encontram na relação entre Lear e Gloucester, e entre Edmundo e as duas irmãs que o desejam; e, novamente, nessas interrelações residem algumas das ironias notáveis que, de outro modo, estariam ausentes da peça. (HEILMAN, 1948, p. 169)

Considerando, portanto, as posturas dos vários críticos acima elencados, é possível alegar que a peça Rei Lear sem o enredo de Gloucester torna-se outra peça, com alcance e potencial trágico bem menor.

Outro acontecimento de relevo eliminado dessa recriação é o banimento de Kent, por discordar da decisão de Lear em dividir seu reino. No texto original, mesmo banido, Kent prova a sua 
fidelidade, ao se disfarçar como o criado Caius e, assim, voltar a servir o Rei que o baniu. Para Coleridge, de todos os personagens de Shakespeare, Kent é o que mais se aproxima da bondade absoluta (citado em BATE, 1992, p. 389). Na recriação, Carneiro mantém Kent ao lado de Lear, que se refere três vezes ao súdito fiel como seu "assessor", como se pode ver na seguinte passagem: "Passados alguns dias, me dirigi a um serviçal, para que chamasse Kent, o meu assessor, pois queria que ele levasse uma carta à minha filha Regan". 5

\section{A concepção do Rei Lear solo}

Tendo estreado em 18 de julho de 2014 no Teatro Eva Herz, em São Paulo, a adaptação de Geraldo Carneiro foi apresentada em muitas outras cidades brasileiras, fazendo uma carreira de sucesso. A semente dessa ideia surgiu por acaso:

Um encontro fortuito resultou em um maravilhoso desafio. Há alguns meses, o ator, diretor e dramaturgo Juca de Oliveira prestigiou um debate do poeta Geraldo Carneiro. $\mathrm{Na}$ conversa, Juca confessou o desejo de interpretar Falstaff ou Lear, dois dos mais notórios personagens criados por William Shakespeare. Carneiro respondeu com um desafio: que tal viver seis personagens de Rei Lear em um monólogo? O ator topou [...]. (BRASIL, 2014, [s.p.])

Foi uma parceria de mútua colaboração: à ideia de Carneiro de um espetáculo solo com seis personagens, Juca de Oliveira respondeu com a sugestão de encerrar a peça no momento em que Cordelia se reencontra com Lear. Não se trata, portanto, de dar um

5 Todas as passagens da encenação citadas foram extraídas de REI Lear, 2014 (vídeo). 
"final feliz" à trajetória de Lear, como se comentou à época - e à semelhança da famosa adaptação de Tate, já mencionada - mas, sim, de finalizá-la antes do final trágico, ou seja, no momento de reconciliação entre pai e filha:

\title{
CORDELIA
}

Vossa Alteza gostaria de dar um passeio comigo?

\section{LEAR}

Vais ter que ter paciência comigo, Cordelia. Eu estou velho, e acho que... até meio caduco.

E saímos os dois a passear. ${ }^{6}$

Em entrevista, o ator apresentou seus motivos para tal proposta:

\begin{abstract}
Quando comecei a trabalhar na ótima tradução e adaptação do Geraldinho, um dos nossos mais inspirados tradutores de Shakespeare, apavorado pelo desafio, saí à caça de gravações de monólogos do Lear, para avaliar as dificuldades que iria enfrentar. Não havia tal monólogo! Nenhum ator fizera antes um monólogo do Lear! Os obstáculos eram tantos, o número de personagens, de cenas, que, a certa altura, apavorado, cancelei o projeto. Mas, ainda assim, continuei buscando uma solução. E, de repente, a luz! Goneril e Regan traem e expulsam o velho pai, tramando sua morte. Cordelia, renegada e expulsa por Lear, vem em seu socorro e o salva. É uma brilhante cena de reconciliação entre pai e filha, a mais bela e comovente da peça, o renascimento da esperança! Claro, o monólogo terminaria aí e ao espectador caberia imaginar o
\end{abstract}

\footnotetext{
${ }^{6}$ Essas falas integram a parte final da cena 7 do Ato IV do Lear shakespeariano, em que o rei reencontra e pede perdão à filha: CORDELIA (to Lear) Will't please your higness walk? LEAR You must bear with me. Pray you now, forget// and forgive. I am old and foolish. (Exeunt) (IV.vi.75-77, SHAKESPEARE, 1988).
} 
futuro de ambos. Li a cena desse reencontro para o Geraldinho, que aprovou. (BRASIL, 2014, [s.p.])

\section{O texto}

As principais características do texto dessa montagem são: (I) o enxugamento da ação, como já mencionado, com o corte da subtrama envolvendo o duque de Gloucester e seus dois filhos, Edmund e Edgar, e um final antecipado, que encerra a peça com o reencontro entre Lear e Cordelia, sem chegar ao desfecho trágico da morte de ambos; (II) o emprego do recurso da narração, situando Lear em um momento cronológico à frente dos fatos que ocorreram, relatando-os e referindo-se a eles no passado; (III) o emprego do recurso do diálogo entre Lear e os outros cinco personagens da trama, em que o ator vive os diferentes papéis e "encena" as interações; (IV) o emprego de uma combinação de prosa, versos brancos e versos rimados nas falas, seguindo o padrão da poesia dramática shakespeariana; e (V) a presença de interpolações de fragmentos de outras obras de Shakespeare.

Em relação ao primeiro aspecto, já foi abordada, aqui, a opção por enxugar a peça abrindo mão do núcleo de Gloucester. Como revelou Carneiro (2018a), seu critério para cortes foi reduzir o texto ao ponto de vista de Lear. A ênfase recaiu, portanto, no drama familiar de Lear e nos riscos inerentes à transferência de dinheiro e poder dos pais para os filhos. Juca de Oliveira ressalta que, quando leu Rei Lear pela primeira vez, teve

um insight que permanece até hoje: os pais, enquanto vivos, jamais deveriam transferir seus bens para o nome dos filhos. Os bens deveriam ser divididos só após a morte, pelo tabelião. E eu estava desgraçadamente certo, pois todos os dias tomamos conhecimento de uma infinidade de pais que cometeram esse erro, desaconselhado por Shakespeare, que sabe tudo sobre o homem. E todos acabaram 
na miséria, abandonados pelos filhos, que se apossaram da herança transferida para seus nomes, na expectativa de afeto e gratidão. Sobre isso, escrevi no programa do espetáculo: "Hoje, com a disparada da longevidade, os filhos modernos, clones de Goneril e Regan (as filhas cruéis), expulsam de casa os velhos pais e os encarceram em asilos até a morte. Puro Shakespeare. Puro Rei Lear". (BRASIL, 2014, [s.p.])

O reencontro de Lear e Cordelia ser o clímax e o final da peça, como já observado, tem o efeito de reduzir o sofrimento que a tragédia impõe, concluindo o relato objetivo e condensado da história do rei com um momento sublime de arrependimento, perdão e redenção.

A segunda característica que se destaca é a opção pelo modo narrativo, com Lear como narrador de uma história que já aconteceu. Nelson de Sá aponta que "Narração - em lugar de ação - é algo que se costuma evitar no palco, mas é até necessário, no caso, devido à adaptação drástica” (2014, s.p.). Como explica o adaptador, Geraldo Carneiro, "Esta adaptação procura recortar os momentos centrais da trajetória de Lear. Claro que há reduções e supressões, mas talvez o personagem tenha ganhado alguma proximidade de nós. Aqui, Lear é sujeito e narrador de sua história" (citado em MELLONE, 2014). Podemos então dizer que há dois Lears, o Lear-Narrador e o Lear-Personagem, sendo a peça ancorada no primeiro, que passa a palavra para os personagens, inclusive o próprio Lear.

Esse deslizamento entre Lear-Narrador e Lear-Personagem ocorrerá ao longo de toda a peça, pois mesmo quando reproduz diálogos da peça original, Geraldo Carneiro recorre ao narrador para inserir explicações sobre a identidade das personagens, como exemplificado no primeiro diálogo entre o rei e a filha mais velha:

\section{LEAR-PERSONAGEM}

Chegou a hora de proclamar os diversos dotes de minhas filhas. Digam-me, minhas filhas - já que agora vou abrir 
mão do governo, da posse das terras e das funções de Estado - qual de vocês podemos dizer que nos tem mais amor?

\section{LEAR-NARRADOR}

Goneril, minha filha mais velha, foi a primeira a falar.

\section{GONERIL}

Senhor, eu te amo mais do que as palavras possam expressar, mais do que a luz dos olhos, o espaço e a liberdade, e mais além do que se considere rico e raro. [...]

A dinamicidade da narração é conferida sobretudo pelo terceiro aspecto a ser ressaltado: os "diálogos" encenados por Lear e seus "interlocutores", moderados pelo narrador. Esse recurso pode ser ilustrado com alguns exemplos: "Depois disso falou minha segunda filha, chamada Regan. - Senhor... sou feita do mesmo metal que minha irmã, ambas de igual valor [...]"; "O nobre Kent, meu amigo e conselheiro, ainda tentou protestar: - Conserva o teu governo, meu senhor, medita, contém esse rompante hediondo!"; "Nisso, passa pela sala o serviçal canalha de minha filha e eu o chamei: Ei, o senhor aí, cavalheiro! Me diga, me diga: Quem sou eu? E ele me respondeu: - O pai de minha senhora"; "Mas a política de corte de pessoal das duas ainda não tinha terminado, e Goneril me interpelou: - Escuta aqui, senhor: para que o senhor necessita de vinte e cinco, ou dez, ou cinco homens, numa casa em que há o dobro de criados para servi-lo?"

O narrador, entre outras intervenções, pode esclarecer o enredo, como nesta fala que se segue à primeira interlocução com Goneril (transcrita acima) e que também introduz o tema da vacuidade das belas palavras:

\section{LEAR-NARRADOR}

Como eram bonitas as palavras de minha filha. Doei a ela e ao marido a terça parte do meu reino. 
O quarto aspecto que chama a atenção na reescrita de Geraldo Carneiro é a manutenção da fórmula prosa/versos brancos/versos rimados que caracteriza a poesia dramática shakespeariana. Há muitas falas em versos brancos, com esquema métrico variado, contemplando desde o decassílabo rigoroso a versos de métrica frouxa, oscilando de nove a até 13 sílabas. Como exemplo do primeiro caso, podemos citar a maldição que Lear lança sobre Goneril, assim que ela reclama de seu séquito, composto de homens "desordeiros, debochados e atrevidos", e decide reduzi-lo:

\author{
Escuta, cara deusa Natureza! \\ Suspende tua intenção, se tu querias \\ Tornar fecunda essa degenerada. \\ Mete a esterilidade no seu ventre! \\ Seca seu útero e que de seu corpo \\ Jamais floresça um filho para honrá-la. \\ [...]
}

Também em decassílabos brancos é a resposta de Regan, a segunda filha, quando Lear vai procurá-la e se queixa de Goneril:

Estás fraco, meu pai, não nos escondas.

Se quiseres voltar para minha irmã

E lá ficares até o fim do mês,

Dispensando a metade da tua escolta,

Depois tu poderás ficar comigo.

Um terceiro exemplo do emprego de decassílabos brancos é a fala de Lear ao se ver colhido pela tempestade:

Sopra, vento, e arrebenta as tuas bochechas!

Despejai cataratas, furacões, 
Até afogar as torres com seus galos!

Relâmpagos de enxofre mais velozes

Que o pensamento, vós, os emissários,

Dos raios que estilhaçam os carvalhos,

Vinde queimar os meus cabelos brancos!

[...]

Por sua vez, a réplica de Lear ao Bobo, já em meio à tempestade, traz versos não rimados de métrica frouxa, predominando o decassílabo.

Sou, sim: em cada polegada, um rei.

Quando encaro, estremecem os meus súditos.

Concedo a vida a esse homem! Qual o seu crime?

Adultério? Não morrerás. Por adultério, não!

$[\ldots]$

As falas rimadas são três, duas do Bobo e uma de Cordelia. Nas falas do primeiro personagem, o tradutor deu prioridade ao significado e à rima (CARNEIRO, 2018b). A primeira fala rimada do Bobo é em dísticos heptassilábicos, com esquema rímico $a a$ bbcc...:

Larga as putas e a bebida,

Fica em casa toda a vida:

E a cada vinte vinténs

Terás o dobro que tens.

Sacou, tio, como é prática

Essa minha matemática?

Aquele que o aconselhou

A dar suas terras, senhor,

Que venha pro meu lugar

Pra ao seu lado figurar. 
A outra fala rimada do Bobo é em dísticos, sem maior rigor métrico, com certo predomínio de hendecassílabos:
Quando o padre fizer o que diz na igreja, O cervejeiro não botar água na cerveja; Quando o nobre proteger o alfaiate, E não pegar doença com a biscate, Quando a justiça for uma coisa séria, E não existir cavalheiro na miséria, Nem escudeiro matando cachorro a grito, Quando não houver intriga no que é dito, E quando a prostituta e o vagabundo Construírem igrejas neste mundo, Então o reino desta velha Albion
Não vai ser nada bom. Não és o rei?

A terceira fala com rimas da peça é atribuída ao personagem Cordelia, no momento de seu reencontro com o pai, que se mostra arrependido de tê-la deserdado e acredita ter perdido o seu amor de filha. Com os olhos cheios de lágrimas (conforme narra Lear), ela diz:
Oh, não, o amor é o sinal mais constante, Que enfrenta a tempestade e não balança, É a estrela-guia dos barcos errantes, Cujo valor lá no alto não se alcança. O amor não é o bufão do Tempo, embora Sua foice vá ceifando a face a fundo. O amor não muda com o passar das horas, Mas se sustenta até o final do mundo. ${ }^{7}$

\footnotetext{
7 “ $\mathrm{O}$, no, it is an ever-fixèd mark//That looks on tempests and is never shaken;// It is the star to every wand'ring bark,//Whose worth's unknown, although his height be taken.//Love's not Time's fool, though rosy lips and cheeks//Within his bending sickle's compass come;//Love alters not with his brief hours and weeks,// But bears it out even to the edge of doom." (SHAKESPEARE, 1980).
} 
Essa fala em decassílabos, com esquema de rimas $a b a b c d c d$, se trata, na verdade, de um fragmento (do quinto ao décimo-segundo verso) do Soneto 116, também de autoria de Shakespeare. Tal interpolação, juntamente com a de uma fala de Hamlet na cena de abertura deste Lear, será abordada mais adiante.

Complementando esta breve análise do texto, cabe fazer alguns comentários sobre a linguagem. Pode-se dizer que tende ao formal, com o emprego de verbos no futuro sintético (caminharei, casarei, dormirei, aborrecerei), ênclises como prendam-na, Digam-me, deixar-vos; vocabulário sofisticado, com palavras como dardejai e expressões como rompante hediondo; aliterações como sua foice vá ceifando a face a fundo; e os pronomes de tratamento tu e vós.

Por outro lado, há também algumas gírias e vocabulário chulo, como na exclamação "Escravo desnaturado, filho da puta", de Lear para um serviçal de Goneril; no comentário de Lear sobre Cordelia: "O mais curioso é que Cordelia, minha filha mais nova, tinha dois pretendentes. Um deles, vendo-a sem dote, com uma mão na frente e a outra atrás, tirou o corpo fora"; e - como se poderia esperar - em algumas falas do Bobo, como "Quando rachaste tua coroa no meio e doaste as duas metades, carregaste o burro nas costas pra cruzar o brejo; tens tão pouco juízo nessa tua coroa, que mandaste pras cucuias a tua coroa de ouro!".

Observa-se, ainda, um trocadilho, feito por Lear falando consigo mesmo:

Honrar a minha idade... Como é que eu vou honrar a minha idade e minha dignidade diminuindo meu séquito? Um homem da minha idade, que já não tem nem mais sexo, precisa de um séquito explícito.

e uma perceptível instabilidade entre $t u$, vós, você e $o$ senhor. No início da peça, Lear se dirige a Goneril, Regan, Cordelia, Kent e o Bobo pela segunda pessoa do singular, e é tratado por eles da mesma forma. Já quando Lear está se queixando de Goneril para 
Regan, esta passa a tratá-lo por vós: "Estais velho, senhor, a natureza em vós já chegou aos seus limites".

Passam-se três falas de Regan, e esta volta a tratar Lear por $t u$, para em seguida retornar a vós. Lear, por sua vez, responde a esse tratamento empregando você: "E você sabe o que está dizendo, Regan?".

Mais uma vez Regan alterna o tratamento, recorrendo agora a $o$ senhor, conjugado na terceira pessoa do singular, ao lado de pronomes de segunda pessoa: "Por que não, meu senhor? Se algum deles falhasse em teu serviço, então nós poderíamos controlá-lo. [...]"

Por fim, no final da peça, na última fala, Lear troca o tratamento de segunda pessoa que vinha mantendo com Cordelia e a chama por você: "Você precisa ter paciência comigo, Cordelia".

O último aspecto importante a ser observado com relação ao texto são as interpolações, que ocorrem por duas vezes: na fala de abertura, por um personagem indefinido, e novamente bem no final da peça, no que é a penúltima fala de Cordelia, como será apresentado a seguir.

O espetáculo começa no escuro, aos poucos, ouvimos ao longe o soar de tambores, mas que cessam quando a luz aumenta e podemos divisar o ator. Juca de Oliveira está sentado em uma cadeira de madeira. Um foco de luz incide sobre o ator. Em voz baixa e solene, ele recita um trecho que não pertence a Rei Lear mas a Hamlet: trata-se do famoso conselho dado pelo príncipe à trupe de atores que visita o castelo de Elsinore e encenará a peça destinada a provocar uma possível confissão de culpa por parte do rei Claudio (Ato III, cena 2).

\section{PERSONAGEM INDEFINIDO}

Peço que fales estas falas, como eu te ensinei: com leveza na língua. Mas se berrares as palavras como tantos atores fazem, eu vou gostar tanto como se ouvisse um arauto lendo minhas frases. E não fiques cortando o ar demais com as mãos. Faz tudo com delicadeza, porque mesmo no meio da torrente, da tempestade, eu diria que no turbilhão da tua 
paixão, é necessário que concebas e te aposses da moderação, que possa dar a ela suavidade. Como me agride a alma ver esses trogloditas de peruca rasgando uma emoção em farrapos, perfurando o tímpano dos infelizes da plateia. $\mathrm{Eu}$ queria ver esse sujeito açoitado. Ele é pior que Herodes. Por favor, evita isso.

O trecho, deslocado de Hamlet e interpolado por iniciativa do diretor Elias Andreato (CARNEIRO, 2018a), não contribui diretamente para contar a história de Lear. Bastante conhecida nas escolas de teatro brasileiras, a passagem trata da arte do ator e de como este deve enunciar as falas, sem gestos excessivos ou sem exageros na interpretação. A passagem funciona, por assim dizer, como uma porta de entrada para um teatro simples, essencial, sem artifícios e que se sustenta na enunciação do texto e na arte do ator. Juca de Oliveira se vale de toda a sua habilidade como ator para que, de modo sutil e sem recorrer a caricaturas, possa interpretar diversos personagens da trama.

Após o conselho aos atores, proferido por uma voz indeterminada, Lear-narrador se apresenta e, em seguida, cede lugar a Lear-personagem. Incorporando Lear no momento em que este abre mão do trono, Juca de Oliveira enuncia a primeira fala do velho rei na peça original, expressando o propósito de dividir o reino entre as filhas:

\section{LEAR-NARRADOR}

Meu nome é Lear, rei Lear. Minha história começa com um gesto de grandeza. Reuni minha corte, minhas três filhas, duas delas já casadas, e proclamei:

\section{LEAR-PERSONAGEM}

Saibam que dividi o meu reino em três, e tenho a intenção de afastar de minha idade avançada todos os encargos e negócios, entregando-os a forças mais jovens, enquanto eu - sem esse fardo - caminharei em direção à morte. 
$\mathrm{Na}$ primeira fala transcrita acima, o adaptador Geraldo Carneiro vai além da apresentação da personagem ("Meu nome é Lear”) e adentra o terreno do comentário crítico. Lear qualifica a divisão do reino como sendo "um gesto de grandeza", interpretação que não constitui ponto pacífico entre os críticos e comentadores. Ao contrário do que o texto da adaptação diz, a divisão do reino pode ser interpretada como um gesto de egoísmo de Lear, em que ele procura afirmar sua ascendência sobre as filhas no momento em que abdica do trono, fazendo-as proclamarem publicamente o amor pelo pai; mais ainda, Lear não compreende que, ao passar o mando do reino às suas filhas e ao mesmo tempo reter um séquito de cem cavaleiros, ele está dissociando os direitos de um soberano dos seus deveres.

Já no final da peça conforme recriada por Carneiro ocorre uma segunda interpolação: quando o pai se reencontra com Cordelia, o texto incorpora algumas linhas, reproduzidas anteriormente neste trabalho, do soneto 116, um dos 154 escritos por Shakespeare. Apenas uma plateia que conheça bem a produção lírica shakespeariana é capaz de reconhecer a citação. Tematicamente, o poema trata do amor, e esta é uma cena em que Lear reconhece que sua filha mais jovem é a única que o ama verdadeiramente, enquanto as mais velhas apenas professavam amor falso, sob o qual se escondia o interesse financeiro. Do mesmo modo, Lear reconhece que ele também ama a filha verdadeiramente, uma vez que recobra a razão de viver graças a esse reencontro.

\section{Cenário, figurino e recursos sonoros}

O único ator em cena, Juca de Oliveira, que dá vida ao Lear narrador e demais personagens, se veste de preto, em roupas confortáveis: camiseta, calça larga, casaco e tênis, sem trocas de roupa no decorrer do espetáculo. O figurino neutro e contemporâneo de Fabio Namatame facilita a incorporação e o deslizamento entre os vários personagens, bem como entre estes e o narrador, sem 
os entraves de vestimentas ou adereços específicos que costumam auxiliar na caracterização dos atores de acordo com seus papéis.

Fotografia 1 - Juca de Oliveira no palco.

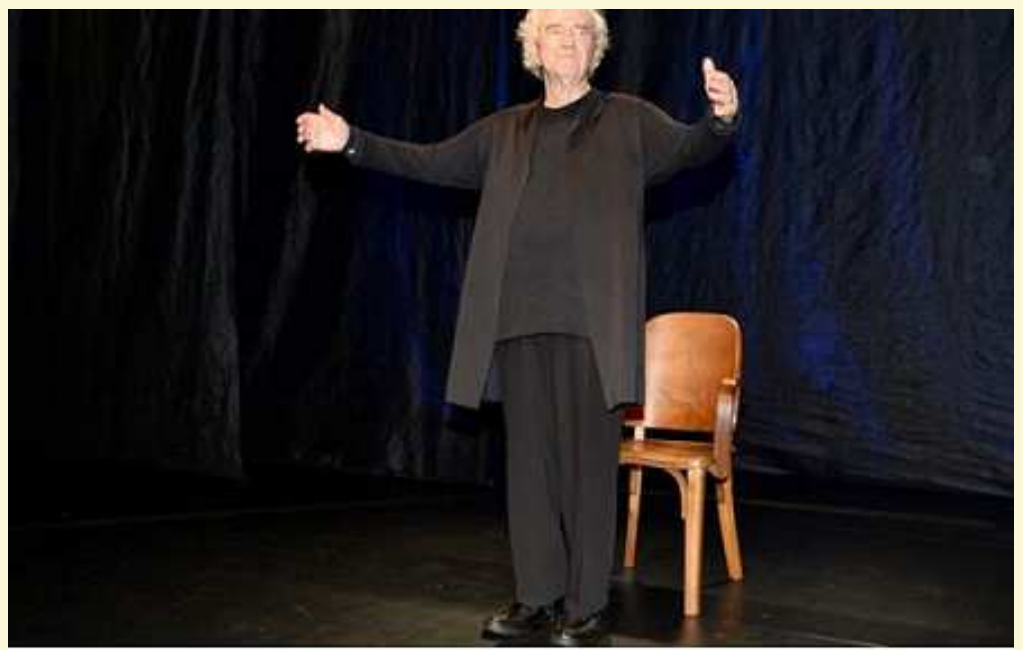

Fonte: Fotografia de Francisco Cepeda (ABILIO, 2014).

O cenário, também concebido por Namatame, é minimalista, sem objetos cênicos, salvo uma cadeira no centro do palco. Nesse sentido, a encenação do diretor Elias Andreato revisita as condições cênicas do teatro elisabetano, de recursos limitados, onde o poder da palavra e a arte dos atores contavam a história, necessitando da imaginação da plateia para completar a ação.

O jogo de luzes sublinha a intensidade das cenas e, junto com a sonoplastia, vai criando os diferentes climas e situações da peça. Em termos de recursos sonoros, no teatro elisabetano predominava o uso da música e das canções. Na montagem de Andreato, os recursos sonoros empregados são incidentais e precedem as cenas-chave, assumindo diferentes funções: criação da atmosfera emocional para as cenas, introdução dos temas, acompanhamento da ação e espelhamento do estado emocional do protagonista. 


\title{
Considerações finais
}

Comparada à Nona Sinfonia de Beethoven e à Capela Sistina, Rei Lear é considerada por muitos críticos como a maior tragédia da língua inglesa e a obra-prima de Shakespeare, tendo merecido comentários críticos e poemas de figuras da magnitude de John Keats (1795-1821), Percy Bysshe Shelley (1792-1822) e Samuel Taylor Coleridge (1772-1834). Enquanto Keats celebra a peça como “a disputa feroz entre tormentos infernais e barro tornado carne" (citado em BATE, 1992, p. 198), para Shelley ela é "o exemplo mais perfeito da arte dramática existente no mundo" (Shelley, 1977, p. 489), e na visão de Coleridge, "um furacão e um redemoinho, que absorvem tudo enquanto avançam" (citado em BATE, 1992, p. 385). A peça é tão admirada por escritores que Charles Lamb (1775-1834) considerou a personagem e a obra grandes demais para o palco, servindo melhor à leitura individual que à encenação:

\begin{abstract}
A grandeza de Lear não está em sua dimensão corporal, mas na intelectual. [...] No palco, não vemos senão as fraquezas e enfermidades corporais [...]; quando lemos a peça, não vemos Lear, mas somos Lear - estamos em sua mente, somos sustentados por uma grandeza que desconcerta a maldade das filhas e da tempestade; nas aberrações de sua razão, descobrimos um poder intenso e irregular de raciocínio". (BATE, 1992, p. 123)
\end{abstract}

A simples tentativa de listar seus temas principais confirma a grandeza da peça: poder, política, autoridade e justiça; reconciliação, religiosidade e renascimento; a relação entre governantes e governados, pais e filhos, patrões e empregados; as oposições entre riqueza e pobreza, loucura e sanidade, visão e cegueira, entre muitos outros. É preciso acrescentar que esses temas se confundem, se entrelaçam e se sobrepõem, criando sua série de motivos e imagens que formam o tecido poético da peça. Em poucas palavras, o dra- 
maturgo nos oferece um retrato devastador do sofrimento humano: velhice, exílio, tortura, guerra, suicídio, caos; o desmantelamento da mente individual, da família e do Estado. Nas palavras de Harold Goddard (1951, p. 171), a peça, que "pode ser vista de quase tantos ângulos como a própria vida", é "o documento mais sombrio na poesia suprema do mundo".

Para os espectadores que não conhecem o original de Shakespeare, a história de Lear como apresentada na recriação de Geraldo Carneiro finda com o reencontro entre pai e filha: Lear pede perdão a Cordelia e se reconcilia com ela. Nesse sentido, pode-se dizer que esta recriação abre mão do conteúdo trágico - uma vez que o protagonista não enlouquece (como narrador, Lear mantém até o fim o controle da narrativa), nem morre - para se tornar uma bela história de reencontro e perdão.

Ficha Técnica:

Texto: William Shakespeare

Tradução e Adaptação: Geraldo Carneiro

Elenco: Juca de Oliveira

Direção: Elias Andreato

Assistente de Direção: André Acioli

Figurino e Cenário: Fabio Namatame

Iluminação: Wagner Freire

Preparação Corporal: Melissa Vettore

Trilha Sonora: Daniel Maia

Fotografia: João Caldas

Logo: Elifas Andreato

Programação Visual: Vicka Suarez

Assessoria de Imprensa: Morente Forte

Gestão de Patrocínios: AT Cultural

Administração / Lei Rouanet: Sodila Projetos Culturais

Direção de Produção: Keila Mégda Blascke 


\section{Referências}

ABILIO, Felipe. Aos 79 anos, Juca de Oliveira estreia monólogo e emociona o público. iG Gente, São Paulo, 18 jul. 2014. Foto de Francisco Cepeda/AgNews SP. Disponível em: < http://gente.ig.com.br/2014-07-18/aos-79-anos-juca-de-oliveiraestreia-monologo-e-emociona-o-publico.html > . Acesso em: 25 mar. 2018.

ACKROYD, Peter. Shakespeare: The Biography. New York: Vintage, 2006.

BATE, Jonathan. The Romantics on Shakespeare. Londres: Penguin, 1992.

BRASIL, Ubiratan. Juca de Oliveira vive seis personagens de Rei Lear. O Estado de S. Paulo, São Paulo, 15 jul. 2014. Disponível em: < http://cultura.estadao. com.br/noticias/teatro-danca, juca-de-oliveira-vive-seis-personagens-de-reilear, 1528633 >. Acesso em: 15 fev 2018.

CARNEIRO, Geraldo. Consulta sobre o Lear com Juca de Oliveira [mensagem pessoal]. Mensagem recebida por <marcia.martins31@gmail.com> em 12 mar. $2018 \mathrm{a}$.

. Consulta sobre o Lear com Juca de Oliveira [mensagem pessoal]. Mensagem recebida por <marcia.martins31@gmail.com> em 13 mar. 2018b.

CAVELL, Stanley. Disowning Knowledge: In: Seven Plays of Shakespeare. Cambridge: Cambridge University Press, 1987.

GODDARD, Harold. The Meaning of Shakespeare. v. 2. Chicago: University of Chicago Press, 1951.

HEILMAN, Robert B. This Great Stage: Image and Structure in King Lear. Baton Rouge: Louisiana State University Press, 1948.

HELIODORA, Barbara. Introdução (a Rei Lear). In: SHAKESPEARE, William. Teatro Completo - Tragédias e Comédias Sombrias. v. 1. São Paulo: Nova Aguilar, 2016. p. 756-757. 
MELLONE, Maurício. Juca de Oliveira brilha como único intérprete da tragédia Rei Lear. Favo do Mellone, São Paulo, 4 ago. 2014. Disponível em: < http:// favodomellone.com. br/juca-de-oliveira-brilha-como-unico-interprete-da-tragedia -rei-lear/ > . Acesso em: 15 fev. 2018.

REI LEAR. Direção: Elias Andreato, Direção de Produção: Karen Megda Blascke. Intérprete: Juca de Oliveira. Curitiba, Paraná. 57'37”. 2014, vídeo. Disponível em: https://www.youtube.com/watch?v=E-egjTf_U6Y. Acesso em: 05 fev. 2018.

RIBNER, Irving. Patterns in Shakespearian Tragedy. New York: Barnes \& Noble, 1960.

SÁ, Nelson de. Juca de Oliveira guia o público pelo drama de um pai em Rei Lear. Folha de S. Paulo, São Paulo, Ilustrada, 17 set. 2014. Disponível em: < http:// www1.folha.uol.com.br/ilustrada/2014/09/1516812-critica-juca-de-oliveira-guiao-publico-pelo-drama-de-um-pai-em-rei-lear.shtml > . Acesso em: 15 fev 2018.

SHAKESPEARE, William. King Lear. The Arden Shakespeare. Editado por Kenneth Muir. Cambridge: Harvard University Press, 1959.

SHAKESPEARE, William. The Poems. Editado por David Bevington. Toronto; New York: Bantam Books, 1980.

SHAKESPEARE, William. The Complete Works. Editado por Stanley Wellse Gary Taylor. Oxford: Clarendon Press, 1988. (Compact Edition)

SHELLEY, Percy Bysshe. A Defense of Poetry. In: POWERS, Sharon; REINAM, Donald (Eds.). Poetry and Prose. New York: Norton, 1977.

TREWIN, J. C. The Pocket Companion to Shakespeare's Plays. ed. ver. Londres: Mitchell Beazley, 1994.

Recebido em: 28/03/2018 Aceito em: 27/07/2018

Publicado em setembro de 2018

Marcia Amaral Peixoto Martins. E-mail: martins@domain.com.br

ORCID: https://orcid.org/0000-0002-8663-1748

Liana de Camargo Leão. E-mail: lianaleao@me.com

ORCID: https://orcid.org/0000-0003-2269-0287 